\title{
The prognostic value of blood glucose and glycosylated haemoglobin estimation in patients with stroke
}

\author{
Neil H. Cox* \& John W. Lorains \\ Clatterbridge Hospital, Clatterbridge Road, Bebington, Wirral, Merseyside L63 4JY, UK.
}

\begin{abstract}
Summary: In a prospective study of 109 patients admitted to hospital with a provisional diagnosis of acute stroke, 87 were found to have acute hemiplegic stroke lasting more than 24 hours, and did not have any other co-existing life-threatening disorder. In 81 of these patients, blood glucose and glycosylated haemoglobin $\left(\mathrm{HbA}_{1}\right)$ were measured at the time of admission. Thirteen of these 81 patients $(16 \%)$ were hyperglycaemic - in 5 cases, normal $\mathrm{HbA}_{1}$ was found in conjunction with hyperglycaemia suggesting that this represented a 'stress' response. There was no significant difference in age or in blood glucose level between those who died as a result of stroke and those who survived. However, hyperglycaemia with normal $\mathrm{HbA}_{1}$ was demonstrated in 4 of 26 patients who died compared to only one of 55 survivors $(P<0.02)$, and all 3 patients with blood glucose greater than $10 \mathrm{mmol} / \mathrm{l}$ in conjunction with normal $\mathrm{HbA}_{1}$ died as a result of stroke. Biochemical evidence of 'stress' hyperglycaemia in patients with acute stroke suggests a poor prognosis.
\end{abstract}

\section{Introduction}

It is well documented that diabetes mellitus is a risk factor for cerebrovascular disease (Jarrett \& Keen, 1975; Kannel \& McGee, 1979) and that previously unrecognized hyperglycaemia increases the risk of stroke and transient ischaemic attacks (Riddle \& Hart, 1982). Fuller et al. (1983) found that the relative risk of death from stroke is increased in patients with diabetes or impaired glucose tolerance, and Asplund et al. (1980) found that diabetics have a poor prognosis after stroke. The fact that hyperglycaemia at the time of stroke is associated with poor outcome (Pulsinelli et al., 1983) is supported by animal studies showing that acute hyperglycaemia at the time of acute cerebral ischaemia results in greater metabolic abnormality in brain tissue and poorer clinical outcome than occurs due to cerebral ischaemia in normoglycaemic controls (Welsh et al., 1978; Siemkowicz \& Gjedde, 1980; Ginsberg et al., 1980).

Melamed (1976) pointed out that hyperglycaemia in 'non-diabetic' patients with stroke may signify either unrecognized pre-existing diabetes or may be a stress response, and in a study of 'non-diabetics' with myocardial infarction it was found that hyperglycaemia was more likely to represent pre-existing diabetes than stress hyperglycaemia (Husband et al., 1983). Stress responses in stroke, assessed by cortisol

*Correspondence and present address: N.H. Cox, B.Sc., M.R.C.P., Western Infirmary, Glasgow G11 6NT, UK. Accepted: 1 August 1985 and catecholamine production (Feibel et al., 1977) or suggested by leukocytosis (Lowe et al., 1983), have an associated poor prognosis. It therefore appears that hyperglycaemia in stroke carries a poor prognosis, whether due to stress response or to diabetes (whether previously recognized or not). To investigate this further, and in particular to determine which of these situations is most important in prognosis, we studied levels of blood glucose and $\mathrm{HbA}_{1}$ and related these to outcome from acute stroke.

Patients, materials and methods

\section{Patients}

One hundred and nine consecutive unselected patients admitted with an initial diagnosis of 'stroke' were entered into a prospective study. Patients with an acute hemiparetic deficit which resolved completely within 24 hours (4 patients) were withdrawn, as were patients in whom an alternative diagnosis (11 patients) or in whom a diagnosis of brainstem stroke (1 patient) was made, in whom a co-existing severe disorder was demonstrated that affected prognosis in its own right (6 patients), or in whom sampling errors occurred (6 patients). Most of those with an alternative diagnosis had suffered fits or had a cerebral neoplasm, but two patients (both insulin-dependent diabetics) had hemiplegia due to hypoglycaemia. Patients with hypoten-

(C) The Fellowship of Postgraduate Medicine, 1986 
sive stroke due to acute myocardial events were considered to have a co-existing disorder affecting prognosis and were withdrawn.

Of the 81 patients in whom stroke was clinically confirmed and from whom venous blood was taken at the time of hospital admission for subsequent measurement of glucose and $\mathrm{HbA}_{1}$, there were 49 males and 32 females with a mean age of 72 years (range 50-92 years). Six patients were known to be diabetic (7.4\%). Follow-up was for 3 months.

\section{Glycosylated haemoglobin measurement}

$\mathrm{HbA}_{1}$ was measured by agar gel electrophoresis using commercially available assay sets (Corning Medical, Halstead, UK) with prior removal of the labile fraction by incubation in saline. This assay system has been described in detail (Menard et al., 1980; Read et al., 1980) and is widely used, in conjunction with high resolution densitometry (Thornton et al., 1981). Normal values in our laboratory, derived from values for 35 non-diabetics, were mean $6.9 \%$, s.d. $0.6 \%$, and hence range (mean \pm 2 s.d.) $5.7-8.1 \%$. Coefficient of variation was $6 \%$, and we therefore considered results of $8.5 \%$ or greater to be abnormal.

\section{Interpretation of biochemical results}

Blood glucose values, taken at the time of admission to hospital, were considered to be abnormal if the result was $8 \mathrm{mmol} / \mathrm{l}$ or greater. The combination of hyperglycaemia with a normal value for $\mathbf{H b A}_{1}$ was interpreted as biochemical evidence of 'stress' hyperglycaemia, a term which we use throughout our results rather than 'acute hyperglycaemia with normal $\mathrm{HbA}_{1}$ '.

\section{Results}

Results for 26 patients who died as a result of stroke $(32 \%)$ were compared with those of the 55 survivors.
There was no significant difference between the age $\frac{0}{\mathrm{~g}}$ patients, or their blood glucose values, in the two groups (Student $t$ test). These results are shown Table I, and the distribution of blood glucose values m Figure 1.

Thirteen patients $(16 \%)$ were hyperglycaemic. $\overrightarrow{\text { बै }}$ these, 8 had raised $\mathrm{HbA}_{1}$ (one of whom died), whilsto had hyperglycaemia but normal $\mathrm{HbA}_{1}$ (four of whow died). Four of the 8 patients who were hyperglycaemoce and had raised $\mathrm{HbA}_{1}$ were known diabetics. There w therefore biochemical evidence of 'stress' hyper glycaemia in 4 of 26 patients who died compared to one of 55 survivors $\left(P<0.02, \chi^{2}\right.$ test). All 3 patien $\bar{B}$ with blood glucose greater than $10 \mathrm{mmol} / \mathrm{l}$ and norma $\mathrm{HbA}_{1}$ (Figure 1) died as a result of stroke $(P<0.02$, test).

A further two patients, both of whom survived, we known diabetics but had normal blood glucose and $\mathrm{HbA}_{1}$ results.

\section{Discussion}

It is important for the patient, his family, and healft care staff to have criteria for predicting outcome $\overline{\mathbf{m}}$ stroke. Lowe et al. (1983) discussed a number of systemic findings which influence prognosis, including age, pre-existing atrial fibrillation, and va\$u of erythrocyte sedimentation rate, globuins, haematocrit, and urea. Allen (1984) has receñtt? reviewed cerebral signs influencing prognosis after stroke. Evidence of stress response is associated wi poor prognosis (Feibel et al., 1977; Asplund et $a_{2,2}$ 1980) and our study suggests that hyperglycaem occurring as part of a 'stress' response is associated with a worse prognosis than if due to pre-existing diabetes. We were unable to demonstrate any correlation between age and survival, although younge patients tended to have better functional recovery. Many previous studies have documented clinical and biochemical evidence that hyperglycaemia per se ad. versely affects outcome in patients with stroke

Table I Age, blood glucose and glycosylated haemoglobin related to outcome in 81 patients with stroke

\begin{tabular}{|c|c|c|c|c|}
\hline Outcome & $\begin{array}{c}\text { Number } \\
\text { (\% of total) }\end{array}$ & $\begin{array}{c}\text { Mean age } \\
(y)\end{array}$ & $\begin{array}{l}\text { Blood glucose } \\
(\text { mmolll })\end{array}$ & $\begin{array}{c}\text { Glycosylated } \\
\text { haemoglobin (\%) }\end{array}$ \\
\hline Died & $26(32 \%)$ & 74.6 & $\begin{array}{c}\text { Range } 3.9-16.3 \\
\text { Mean } 6.5 \\
\text { s.d. } 2.6\end{array}$ & $\begin{array}{c}\text { Range } 5.7-11.5 \\
\text { Mean } 7.4 \\
\text { s.d. } 1.1\end{array}$ \\
\hline Survived & $55(68 \%)$ & 70.8 & $\begin{array}{c}\text { Range } 3.9-12.1 \\
\text { Mean } 6.1 \\
\text { s.d. } 1.8\end{array}$ & $\begin{array}{c}\text { Range } 4.0-13.0 \\
\text { Mean } 7.6 \\
\text { s.d. } 1.6\end{array}$ \\
\hline
\end{tabular}




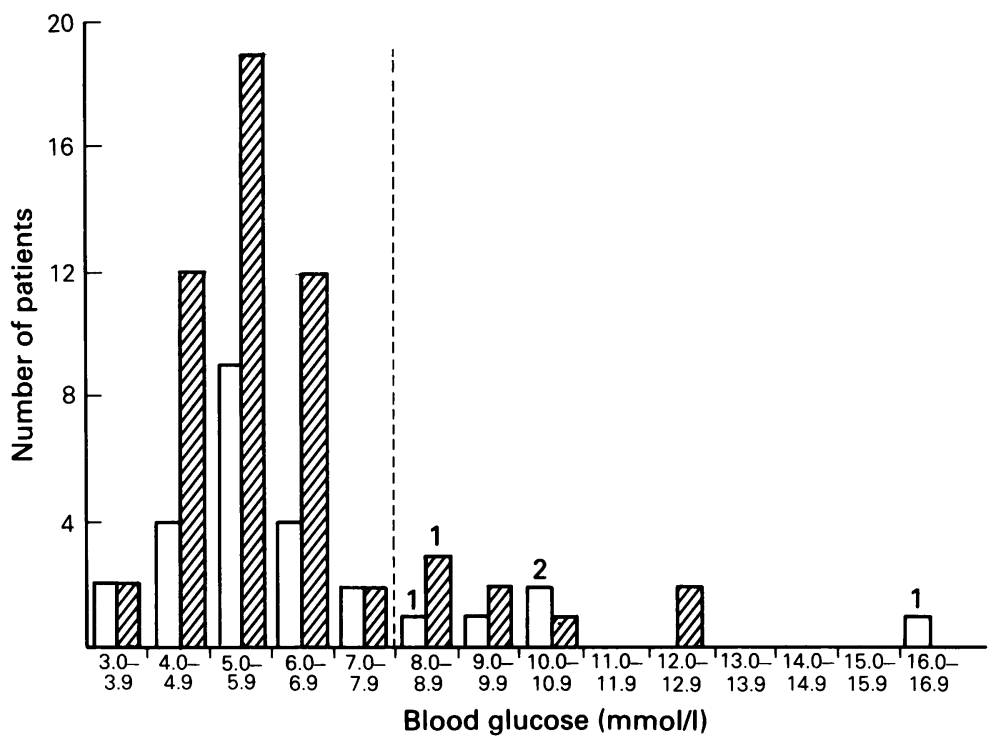

Figure 1 Distribution of blood glucose values in 81 patients with stroke. Values are expressed related to outcome, either deaths (26 patients, $\square$ ) or survival (55 patients, $\square$ ). Values of $8 \mathrm{mmol} / 1$ or greater (to right of vertical dashed line) were considered to be hyperglycaemic. Figures above the blocks of hyperglycaemic values are the number of patients with normal $\mathbf{H b A}_{1}$ and hyperglycaemia, suggesting 'stress hyperglycaemia'.

(Asplund et al., 1980; Riddle \& Hart, 1982; Pulsinelli et al., 1983; Fuller et al., 1983).

A variety of metabolic disturbances occur as a result of cerebral ischaemia, including lactic acidosis, altered cerebral blood flow, decrease in glutathione pool, and impaired oxidative phosphorylation and ATP production (Myers \& Yamaguchi, 1976; Siemkowicz \& Gjedde, 1980; Rehncrona, 1980; Siemkowicz, 1981). Hyperglycaemia causes a greater reduction in cerebral oxygen consumption post-ischaemia than occurs in normoglycaemic controls and is associated with a greater degree of local cerebral lactic acidosis. These facts suggest that anaerobic glycolysis (and resultant lactic acidosis) may be prolonged if cerebral ischaemia occurs in the presence of hyperglycaemia. Siemkowicz \& Gjedde (1980) showed that normoglycaemic recirculation after cerebral ischaemia preceded by hyperglycaemia resulted in recovery as complete as in controls which had been normoglycaemic throughout, and also that in hyperglycaemic rats, post-ischaemic seizure activity was reduced more by normoglycaemic recirculation or by insulin treatment of the hyperglycaemia than by anticonvulsant therapy. Although these results suggest that active treatment of hyperglycaemia in patients with stroke may be helpful, extrapolation of results of short-term hyperglycaemia due to exogenous glucose administration may not be valid in the case of diabetics (in whom there may be cerebral metabolic changes due to chronic hyper- glycaemia) or in patients with 'stress' responses (in whom other metabolic changes occur). Site and severity of cerebral injury may be important in causation of 'stress' hyperglycaemia, and it may be these factors rather than the degree of hyperglycaemia which determine the prognosis. In spite of this uncertainty regarding the relationship of animal experiments and the situation in man, it is interesting that we knew of two patients who received $50 \%$ glucose intravenously before arrival in hospital, both of whom died - one died before reaching hospital and could therefore not be included in the study, whilst the other had a blood sugar of over $10 \mathrm{mmol} / \mathrm{l}$ with normal $\mathrm{HbA}_{1}$ and died on the day of admission.

It is not clear why there were fewer diabetic and hyperglycaemic patients in our study than in other prospective studies. Riddle \& Hart (1982) had 10 patients with known diabetes or impaired glucose tolerance in their series of 50 patients $(20 \%)$, compared to our 6 of $81(7.4 \%)$ - however, patients with transient ischaemic attacks were included in their series but not in ours, and we did find a further 4 patients with raised $\mathrm{HbA}_{1}$ and blood glucose of over $8 \mathrm{mmol} / 1$ suggesting a total of 10 diabetics in our 81 patients $(12.3 \%)$. Pulsinelli et al. (1983) found 14 of their 31 patients $(45 \%)$ to have blood glucose of over $6.7 \mathrm{mmol} / 1$ compared to 21 of $81(26 \%)$ in our somewhat larger series.

We have presented results suggesting that hyper- 
glycaemia in conjunction with normal $\mathrm{HbA}_{1}$, which probably represents a 'stress' response, is associated with poor prognosis for recovery from stroke. We suggest that measurement of $\mathrm{HbA}_{1}$ is a relatively simple investigation which, when used in conjunction with measurement of acute blood glucose, may add to the prognostic information for patients with stroke. A controlled trial of active intervention to treat hyperglycaemia in patients with stroke appears to be required.

\section{Addendum}

Since this paper was accepted for publication, we have learnt of a further study of $\mathrm{HbA}_{1}$ in stroke performed at the same time as our study. Oppenheimer et al. (1985) studied 100 patients with stroke, of whom 8 were known diabetics and 6 previously undiagnosed diabetics (these figures being similar to our 6 of 81

\section{References}

ALLEN, C.M.C. (1984). Predicting recovery after acute stroke. British Journal of Hospital Medicine, 31, 428.

ASPLUND, K., HÄGG, E., HELMERS, C., LITHNER, F., STRAND, T. \& WESTER, P-O. (1980). The natural history of stroke in diabetic patients. Acta Medica Scandinavica, 207, 417.

FEIBEL, J.H., HARDY, P.M., CAMPBELL, R.G., GOLDSTEIN, M.N. \& JOYNT, R.J. (1977). Prognostic value of the stress response following stroke. Journal of the American Medical Association, 238, 1374.

FULLER, J.H., SHIPLEY, M.J., ROSE, G., JARRETT, R.J. \& KEEN, H. (1983). Mortality from coronary heart disease and stroke in relation to degree of glycaemia: the Whitehall study. British Medical Journal, $287,867$.

GINSBERG, M.D., WELSH, F.A. \& BUDD, W.W. (1980). Deleterious effect of glucose pre-treatment on recovery from diffuse cerebral ischemia in the cat. I. Local cerebral blood flow and glucose utilization. Stroke, 11, 347.

HUSBAND, D.J., ALBERTI, K.G.G.M. \& JULIAN, D.G. (1983). 'Stress' hyperglycaemia during acute myocardial infarction: an indicator of pre-existing diabetes? Lancet, i, 179.

JARRETT, R.J. \& KEEN, H. (1975). Diabetes and atherosclerosis. In Complications of diabetes, Keen, H. \& Jarrett, R.J. (eds). p.179. Edward Arnold: London.

KANNEL, W.B. \& McGEE, D.L. (1979). Diabetes and cardiovascular disease: the Framingham study. Journal of the American Medical Association, 241, 2035.

LOWE, G.D.O., JAAP, A.J. \& FORBES, C.D. (1983). Relation of atrial fibrillation and high haematocrit to mortality in acute stroke. Lancet, ii, 784.

MELAMED, E. (1976). Reactive hyperglycaemia in patients with acute stroke. Journal of the Neurological Sciences, 29, 267.

MENARD, L., DEMPSEY, M.E., BLANKSTEIN, L.A., ALEYASSINE, H., WACKS, M. \& SOELDNER, J.S. (1980). Quantitative determination of glycosylated haemoglobin $A_{1}$ by
$(7.4 \%)$ and 4 of $81(4.9 \%)$ respectively). This stuक्षिy demonstrated that $\mathrm{HbA}_{1}$ and plasma glucose hada highly significant correlation, and that elevated $\mathrm{Hb}$ was associated with early mortality and poor prognosis in patients with stroke. This result supports oun view that measurement of $\mathrm{HbA}_{1}$ may be useful, further studies are required to determine the ex $\Rightarrow \mathrm{ct}$ significance of paired blood glucose and $\mathrm{HbA}_{1}$ resules.

We are grateful to Mrs Joan South for her help om information regarding $\mathrm{HbA}_{1}$ measurement, and to all he Junior Staff who co-operated with obtaining blood samples. Dr W. Watson kindly gave advice regarding statistíal assessment. agar gel electrophoresis. Clinical Chemistry, 26, 1958. MYERS, R.E. \& YAMAGUCHI, M. (1976). Effects of serūm glucose concentration on brain response to circulatôry arrest. Journal of Neuropathology and Experimenal Neurology, 35, 301.

OPPENHEIMER, S.M., HOFFBRAND, B.I., OSWALD, GA YUDKIN, J.S. (1985). Diabetes mellitus and early mo ality from stroke. British Medical Journal, 291, 1014.

PULSINELLI, W.A., LEVY, D.E. SIGSBEE, B., SCHERER, P P \& $\&$ PLUM, F. (1983). Increased damage after ischemic strok patients with hyperglycaemia with or without establis diabetes mellitus. American Journal of Medicine, 74, 540.

READ, A., TIBI, L. \& SMITH, A.F. (1980). Assessment of simple electrophoretic method for measuring $\mathrm{HbAq}$. Clinica Chimica Acta, 126, 257.

REHNCRONA, S. (1980). Biochemical factors influencing recovery in brain ischaemia. Acta Neurologica Scandinavica (Supplement), 78, 167.

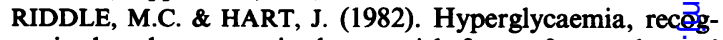
nized and unrecognized, as a risk factor for stroke a transient ischemic attacks. Stroke, 13, 356.

SIEMKOWICZ, E. \& GJEDDE, A. (1980). Post-ischemic cogुa in rat: effect of different pre-ischemic blood glucose levels on cerebral metabolic recovery after ischemia. Afta Physiologica Scandinavica, 110, 225.

SIEMKOWICZ, E. (1981). Hyperglycaemia in the re-perfusiłon period hampers recovery from cerebral ischemia. $A$ 鱼a Neurologica Scandinavica, 64, 207.

THORNTON, W.E., SCHELLEKENS, A.P.M. \& SANDERS, G.T.B. (1981). Assay of glycosylated haemoglobin using agar gel electrophoresis. Annals of Clinical Biochemist;, 18, 182.

WELSH, F.A., GINSBERG, M.D., RIEDER, W. \& BUDD, W.W. (1978). Impairment of metabolic recovery from cerebol ischemia by prior administration of glucose. Federat Proceedings, 37, 873. 